\title{
Knowledge of COVID-19 and Health Literacy among Patients Seeking Care in an Emergency Department
}

\author{
Connor Barry ${ }^{1}$, Stephen Green ${ }^{1}$, Brian Payne ${ }^{2}$, MD, Justin Holmes ${ }^{2}$, MD, K. Tom Xu ${ }^{* 2}$, MD PhD \\ ${ }^{1}$ School of Medicine, Texas Tech University Health Sciences Center, Lubbock TX \\ ${ }^{2}$ Division of Emergency Medicine, Department of Surgery, Texas Tech University Health Sciences Center, \\ Lubbock TX
}

*Corresponding author: K. Tom Xu, MD PhD; Tom.Xu@ttuhsc.edu

Received 23 November 2021;

Accepted 29 November 2021;

Published 01 December 2021

\begin{abstract}
Background: As the US continues to experience increases of COVID-19 cases, there is an urgent need to identify ways to improve individuals' knowledge of COVID-19 to achieve effective prevention and vaccination. The primary objective of the current study was to examine whether the knowledge of COVID-19 was associated with the general health literacy among patients in an emergency department. Methods: A sample of 252 adults was collected in an urban ED. Patients' knowledge of COVID-19 was measured by the agreement to 10 statements. Health literacy was measured by the Brief Health Literacy Screen (BHLS). Participants were also asked about their primary source of COVID-19 information, sociodemographics, comorbidities and familiarity with the healthcare system at baseline. Bivariate and multivariate analyses were conducted. Results: The average COVID-19 knowledge score was 7.09 (range 0-10) and BHLS score, 11.09 (range 3-15). About 43\% obtained the information primarily from TVs, radios, and newspapers and only $8 \%$ from scientific sources. The group with the primary source being social media had the lowest average COVID-19 knowledge score of 6.25. The BHLS and COVID-19 knowledge scores were positively correlated in both bivariate and multivariate analyses. Compared to primary source of information being social media, internet sites and searches $(\mathrm{p}=0.03$ ) and families, relatives, and friends $(\mathrm{p}=0.02)$ were associated with higher COVID-19 knowledge scores, controlling for other factors. Education and income levels were statistically significant in both the bivariate and regressions. Conclusions: Patients with better general health literacy had better knowledge of COVID-19. To better prevent further increases in COVID-19 transmission and improve the rate of vaccination, individuals of low educational and income levels should be prioritized in community interventions. Regulations on and/or guard against misinformation presented on social media platforms should be included in any effective interventions to improve individuals' knowledge of COVID-19.
\end{abstract}

Keywords: COVID-19, health literacy, disease prevention, health disparities

\section{Background}

COVID-19 has changed Americans' health behavior in a dramatic way. New scientific discoveries alongside an abundance of information and misinformation have created confusion in public perception of COVID-19. For example, the Centers for Disease Control (CDC) did not encourage wearing face masks at the start of the pandemic but reversed that decision in April of 2020 by stating masks do have some level of benefit and should be worn by the public ${ }^{[1,2]}$.

It is well established that a lower level of health literacy is associated with worse health outcomes ${ }^{[3-5]}$. One particularly important role of health literacy is to improve patients' ability to understand the prevention, treatment, and prognosis of infectious diseases which leads to more effective personal prevention strategies and coping mechanisms. A study from 2016 showed that a low health literacy with infectious diseases, such as tuberculosis, malaria and influenza, was associated with decreased protective behaviors and understanding of antibiotic usage ${ }^{[6]}$. The same study also demonstrated that patients with a lower health literacy score were less likely to be currently vaccinated and less likely to receive future vaccine as compared to patients with a higher health literacy score. Additionally, in a study focused on outpatient antibiotics prescribed in emergency departments (EDs), patients with low health literacy had a decreased number of prescriptions filled at 3 days ${ }^{[7]}$.

It should be recognized that health literacy is a broad concept of a person's ability to obtain and comprehend health information for health-related decision-making ${ }^{[8]}$. Health knowledge, on the other hand, measures the cognition of health concepts and medical terminology, and usually is measured for a particular disease or intervention in clinical and public health 
studies. Although in general, lower health literacy was associated with less health knowledge in various diseases, ${ }^{[9-12]}$ the positive correlation is not universally observed ${ }^{[13,14]}$. Because COVID-19 is still a new disease entity, it is unclear whether individuals' overall health literacy is associated with their knowledge of COVID-19. The primary objective of the current study was to examine whether better knowledge of COVID-19 was associated with patients' overall health literacy among patients seeking care in an ED. The secondary objective was to demonstrate whether patients' primary source of COVID-19 information was associated with their COVID-19 knowledge.

\section{Methods}

A convenience sample was collected in an urban ED of an annual average volume of 80,000 . Approval from the local Institutional Review Board (IRB) was obtained prior to the start of the study. The duration of the study was a 6 -week period from $05 / 25 / 2020$ to $07 / 05 / 2020$. Written consents were obtained. A total of 252 participants completed the study, exceeding the minimal sample size of 220 calculated by the initial power analysis using a beta of $99 \%$ and alpha of $5 \%$. A commercial online platform, QualtricsXM, was used for data collection from a survey. The inclusion criteria were 1) currently seeking ED care; 2) 18-89 years of age; and 3) Glasgow Coma Scale (GCS) of 15. Patients aged 17 years or younger, psychiatric patients and trauma activations were excluded. Patients in ED rooms who met the inclusion criteria were briefed with a verbal description of the study and the study flyer was given. After they decided to voluntarily participate, they could choose between completing the survey online on their phone or computer at any time during the study period and completing the survey in the room while waiting for care to be completed with the assistance of a medical student who helped the patient utilize a tablet device.

Patients' knowledge of COVID-19 was examined by answers to whether they agreed to a mix of 10 correct and incorrect statements about COVID-19 that included basic epidemiology, prevention, diagnosis, treatment, and prognosis. Because the studies of COVID-19 knowledge were extremely scarce at the beginning of the COVID-19 pandemic, we modified an instrument used for healthcare workers to include the most up-to-date information about COVID-19 at that time and be used for patients ${ }^{[15]}$. Face validity was obtained among all researchers involved in the current study and additional clinicians. The total number of correct answers was used as the COVID-19 knowledge score.

1. COVID-19 or the novel coronavirus is a bacterial infection. (F)

2. You can get COVID-19 through contact with an infected person. (T)

3. Face masks, and frequent hand washing or use of hand sanitizer can prevent getting COVID-19. (T)

4. You don't have COVID-19 if you don't have any symptoms. (F)

5. Fever, cough, and shortness breath are the most likely symptoms of COVID-19. (T)

6. People with chronic health problems, such as high blood pressure, diabetes, heart disease and kidney disease, are more likely to get COVID-19 and die. (T)

7. All COVID-19 patients require treatment of antibiotics. (F)

8. COVID-19 vaccine is available now in the US. (F)

9. More than half of people who had COVID-19 died. (F)
10. COVID-19 is more deadly among young persons and children. $(\mathrm{F})$

Health literacy was measured by the Brief Health Literacy Screen (BHLS) that has been demonstrated to have good concordance with several commonly used instruments measuring health literacy, such as REALM (Rapid Estimate of Adult Literacy in Medicine), and S-TOFHLA (Short Test of Functional Health Literacy in Adults) ${ }^{[16-18]}$. BHLS has been tested in a wide variety of clinical settings including EDs, and can be self-administered ${ }^{[19-21]}$. The BHLS uses three questions with each question scored on a 5-point Likert scale: always (1), often (2), sometimes (3), rarely (4) and never (5). The summation represents the final BHLS score.

1. How often do you have problems learning about your medical condition because of difficulty understanding written information?

2. How confident are you filling out medical forms by yourself?

3. How often do you have someone help you read hospital materials?

Because there were diverse sources of information about COVID19 , participants were asked about their primary source of COVID19 information. The replies were grouped into 5 categories: social media, internet sites and searches, $3{ }^{\text {rd }}$-party reports (TVs, radios, and newspapers), scientific sources (CDC and professional journals), and families, relatives and friends.

Patients' sociodemographic information was also collected in the survey: age, gender, race, education level, employment status, household income and primary language spoken at home. About $7 \%$ of the participants primarily spoke Spanish at home. According to the Census 2000, only about $6.6 \%$ of the local county population reported speaking English less than "very well." Frequency of ED visits in 2019 and the frequency of outpatient clinic visits in 2019 were collected to gauge participants' familiarity and interaction with the healthcare system at the baseline prior to the COVID-19 pandemic, whether they had a primary care provider (PCP), and whether they had any comorbidities (hypertension, hyperlipidemia, diabetes, heart diseases, chronic kidney disease, stroke, and liver diseases).

Statistic software Stata (StataCorp, College Station, TX) was used for analyses. Distributions of the COVID-19 knowledge and BHLS scores were first examined. Descriptive statistics of the primary source of COVID-19 information, participants' sociodemographics and familiarity and interaction with the healthcare system were reported. Bivariate analysis between the COVID-19 knowledge score and each independent variable was conducted. A multivariate regression was conducted to examine the independent associations of BHLS and the primary source of COVID-19 information and the COVID-19 knowledge score, respectively, controlling for the confounding of patients' sociodemographics and familiarity and interaction with the healthcare system.

\section{Results}

Figures 1 and 2 depict the distributions of the COVID-19 knowledge and the BHLS scores. Descriptive statistics of variables of interest are reported in the second column of Table 1. The average COVID-19 knowledge score was 7.09 (range 0-10) and BHLS score, 11.09 (range 3-15). About 8\% obtained the information primarily from scientific sources. In contrast, $43 \%$ obtained the information primarily from TVs, radios, and 
newspapers. Approximately 17\%, 16\% and 16\% reported the primary source as Internet site/searches, social media, and families and friends, respectively.

Approximately $16 \%$ of the sample was elderly (65+) and slightly over half were females. Hispanics and other racial minorities consisted of about $45 \%$ and $15 \%$ of the sample, respectively. Only about $15 \%$ did not finish high school. Approximately $32 \%$ were unemployed. Slightly over $40 \%$ of the participants had an annual household income $<\$ 25,000$. Only about $7 \%$ of the participants reported that the primary language spoken at home was not English. Slightly over $2 / 3$ had a primary care provider. More than half had at least one chronic disease. Approximately $13 \%$ and $31 \%$ had $>5$ visits to ED and outpatient clinics, respectively, in 2019.

Results from bivariate analyses are reported in the $3 \mathrm{rd}$ and 4 th columns of Table 1 . The results demonstrated statistically significant $(\mathrm{p}<0.05)$ correlations between COVID-19 knowledge and BHLS, as well as COVID-19 knowledge and the primary source of COVID-19 information. A higher BHLS score was correlated with a higher COVID-19 knowledge score. The group with the primary source being families, relatives and friends had the highest average COVID-19 knowledge score of 8.22, whereas the one with the primary source of social media had the lowest average score of 6.25. Bivariate analyses showed that the COVID19 knowledge score was significantly $(\mathrm{p}<0.05)$ associated with patients' race and ethnicity, education level, employment status, household income, and whether patients had a primary care provider.

The results from the multivariate analysis are shown in Table 2. Even after controlling for the confounding variables, BHLS was still found to be statistically significant $(\mathrm{p}=0.03)$. Internet sites and searches were associated with higher COVID-19 knowledge scores when compared to primary source of information being social media $(\mathrm{p}=0.03)$. Families, relatives, and friends as the primary source of information was also associated with higher COVID-19 knowledge scores when compared to social media $(\mathrm{p}=0.02)$. In contrast to the results from bivariate analyses, participants' employment status, race and whether patients had a primary care provider were no longer statistically significant after controlling for confounding variables. Compared to patients who did not graduate high school, those with an education level higher than high school had a significantly higher COVID-19 knowledge score by $1.61 \quad(\mathrm{p}<0.01)$. No significant difference was found between high school graduates and those who did not graduate high school. Lastly, lower income was associated with a lower COVID-19 knowledge score by $0.67(\mathrm{p}=0.02)$.

Table 1: Descriptive Statistics and Bivariate Analyses (N=252)

\begin{tabular}{|c|c|c|c|}
\hline & $\begin{array}{l}\text { Proportion or } \\
\text { Mean (std.) - Full Sample }\end{array}$ & $\begin{array}{l}\text { Mean COVID Knowledge } \\
\text { Score in Subgroup }\end{array}$ & $\begin{array}{l}\text { p value for Bivariate } \\
\text { Analyses }\end{array}$ \\
\hline COVID Knowledge Score & $7.09(2.17)$ & --- & --- \\
\hline BHLS Score & $11.09(3.21)$ & --- & $<0.01$ \\
\hline Primary Source of Information for COVID-19 & & & 0.01 \\
\hline Social Media & $15.87 \%$ & 6.25 & \\
\hline Internet Sites and Searches & $17.46 \%$ & 7.77 & \\
\hline 3rd-Party Reports (TVs, Radios and Newspapers) & $42.86 \%$ & 6.73 & \\
\hline Scientific Sources (CDC and Professional Journals) & $7.54 \%$ & 6.89 & \\
\hline Families, Relatives \& Friends & $16.27 \%$ & 8.22 & \\
\hline Age & & & 0.96 \\
\hline$<=40$ yo & $40.48 \%$ & 7.06 & \\
\hline $41-64$ yo & $43.25 \%$ & 7.09 & \\
\hline $65+$ & $16.27 \%$ & 7.17 & \\
\hline Gender & & & 0.89 \\
\hline Male & $42.06 \%$ & 7.11 & \\
\hline Female & $57.94 \%$ & 7.08 & \\
\hline Race and Ethnicity & & & $<0.01$ \\
\hline Non-Hispanic White & $40.48 \%$ & 7.67 & \\
\hline Hispanic & $44.84 \%$ & 6.87 & \\
\hline Other races & $14.68 \%$ & 6.19 & \\
\hline Education & & & $<0.01$ \\
\hline$<$ High School & $15.08 \%$ & 5.89 & \\
\hline High School & $53.17 \%$ & 6.81 & \\
\hline > High School & $31.75 \%$ & 8.13 & \\
\hline Employment & & & 0.02 \\
\hline Full Time & $42.46 \%$ & 7.45 & \\
\hline Part Time & $11.11 \%$ & 6.79 & \\
\hline Retired & $14.68 \%$ & 7.49 & \\
\hline Unemployed & $31.75 \%$ & 6.54 & \\
\hline Household Annual Income & & & $<0.01$ \\
\hline$>=\$ 25,000$ & $59.52 \%$ & 7.63 & \\
\hline$<\$ 25,000$ & $40.48 \%$ & 6.30 & \\
\hline Primary Language Spoken at Home & & & 0.53 \\
\hline English & $92.86 \%$ & 7.12 & \\
\hline Other Languages & $7.14 \%$ & 6.78 & \\
\hline
\end{tabular}


International Journal of Innovative Research in Medical Science (IJIRMS)

\begin{tabular}{|l|l|l|l|}
\hline Have Primary Care Provider & & & $<0.01$ \\
\hline No & $30.16 \%$ & 6.33 & \\
\hline Yes & $69.84 \%$ & 7.42 & 0.85 \\
\hline Any Comorbidities & & & \\
\hline No & $45.44 \%$ & 7.06 & \\
\hline Yes & $55.56 \%$ & 7.11 & 0.53 \\
\hline Annual ED Visits in 2019 & & & \\
\hline $0-2$ & $75.40 \%$ & 7.17 & \\
\hline $3-5$ & $11.90 \%$ & 6.70 & \\
\hline$>5$ & $12.70 \%$ & 7.00 & 0.47 \\
\hline Annual Outpatient Clinic Visits in 2019 & & & \\
\hline $0-2$ & $43.25 \%$ & 6.97 & \\
\hline $3-5$ & $25.40 \%$ & 6.98 & \\
\hline$>5$ & $31.35 \%$ & 7.34 & \\
\hline
\end{tabular}

*: $p$ value of the bivariate analysis of the COVID knowledge score and the independent variable

Table 2: Multivariate Analysis Results ( $=252)$

\begin{tabular}{|c|c|c|c|}
\hline & Est. & p value & $95 \% \mathrm{CI}$ \\
\hline BHLS score & $\mathbf{0 . 1 0 2}$ & $\mathbf{0 . 0 3}$ & $(0.012,0.192)$ \\
\hline \multicolumn{4}{|l|}{ Primary Source of Information for COVID-19 } \\
\hline \multicolumn{4}{|l|}{ Social Media } \\
\hline Internet Sites and Searches & 0.967 & $\mathbf{0 . 0 3}$ & $(0.090,1.844)$ \\
\hline 3rd-Party Reports (TVs, Radios and Newspapers) & 0.083 & 0.83 & $(-0.663,0.829)$ \\
\hline Scientific Sources (CDC and Professional Journals) & 0.433 & 0.45 & $(-0.683,1.550)$ \\
\hline Families, Relatives \& Friends & 1.137 & $\mathbf{0 . 0 2}$ & $(0.220,2.054)$ \\
\hline \multicolumn{4}{|l|}{ Age } \\
\hline \multicolumn{4}{|l|}{$<=40$ yo } \\
\hline 41-64 yo & -0.009 & 0.98 & $(-0.603,0.585)$ \\
\hline $65+$ & -0.110 & 0.84 & $(-1.147,0.927)$ \\
\hline Female (vs. Male) & -0.379 & 0.15 & $(-0.898,0.139)$ \\
\hline \multicolumn{4}{|l|}{ Race and Ethnicity } \\
\hline \multicolumn{4}{|l|}{ Non-Hispanic White } \\
\hline Hispanic & 0.032 & 0.92 & $(-0.577,0.641)$ \\
\hline Other races & -0.601 & 0.14 & $(-1.396,0.194)$ \\
\hline \multicolumn{4}{|l|}{ Education } \\
\hline \multicolumn{4}{|l|}{$<$ High School } \\
\hline High School & 0.527 & 0.18 & $(-0.242,1.296)$ \\
\hline > High School & 1.437 & $\mathbf{0 . 0 0}$ & $(0.557,2.317)$ \\
\hline \multicolumn{4}{|l|}{ Employment } \\
\hline \multicolumn{4}{|l|}{ Full Time } \\
\hline Part Time & -0.557 & 0.20 & $(-1.411,0.298)$ \\
\hline Retired & 0.189 & 0.71 & $(-0.798,1.175)$ \\
\hline Unemployed & -0.347 & 0.31 & $(-1.017,0.322)$ \\
\hline Income $<\$ 25 \mathrm{~K}$ (vs. $>=\$ 25 \mathrm{~K})$ & -0.599 & 0.04 & $(-1.171,-0.027)$ \\
\hline Non-English Spoken at home (vs. English) & 0.849 & 0.11 & $(-0.194,1.893)$ \\
\hline Any Comorbidities (vs. Not) & 0.129 & 0.67 & $(-0.467,0.726)$ \\
\hline Have PCP (vs. Not) & 0.428 & 0.17 & $(-0.188,1.043)$ \\
\hline \multicolumn{4}{|l|}{ Annual ED Visits in 2019} \\
\hline \multicolumn{4}{|l|}{$0-2$} \\
\hline $3-5$ & -0.081 & 0.84 & $(-0.879,0.717)$ \\
\hline$>5$ & 0.006 & 0.99 & $(-0.864,0.877)$ \\
\hline \multicolumn{4}{|l|}{ Annual Outpatient Clinic Visits in 2019} \\
\hline \multicolumn{4}{|l|}{$0-2$} \\
\hline $3-5$ & -0.100 & 0.76 & $(-0.747,0.548)$ \\
\hline$>5$ & 0.583 & 0.09 & $(-0.090,1.256)$ \\
\hline
\end{tabular}




\section{COVID Knowledge Score}

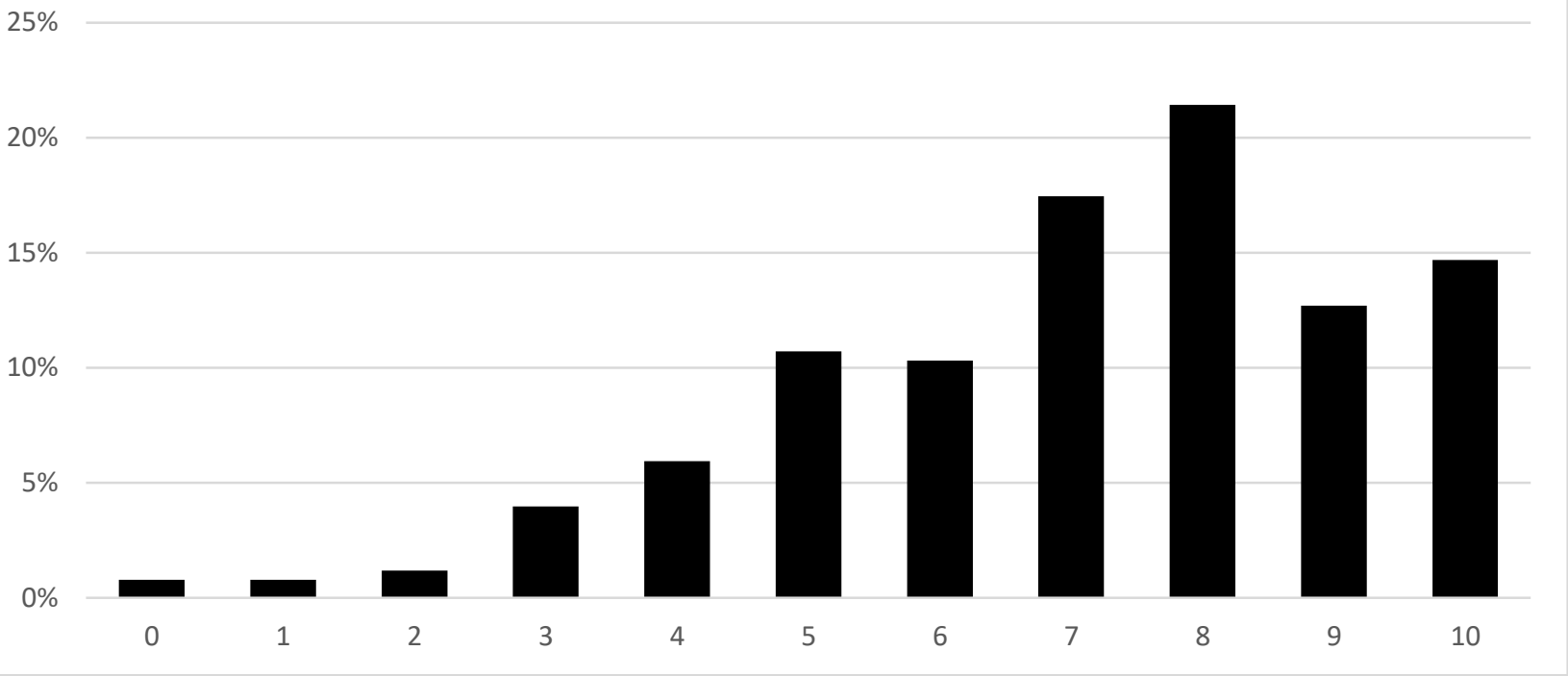

Figure 1: COVID Knowledge Score $(\mathrm{N}=252)$

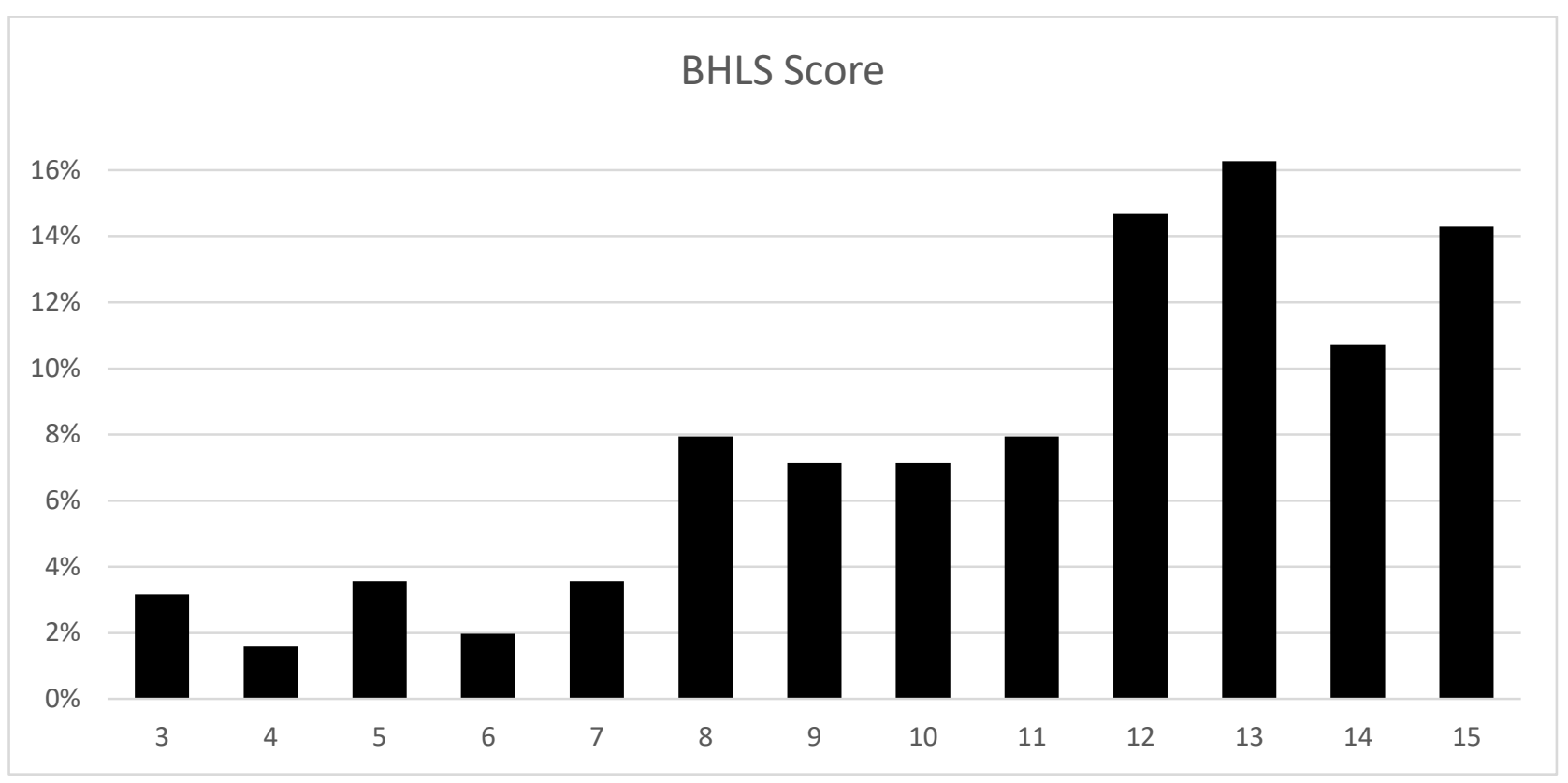

Figure 2: BHLS Score $(\mathrm{N}=\mathbf{2 5 2})$

\section{Discussion}

There are several limitations in the current study. First, the current study examined only ED patients. The results may not be representative of the general population who do not seek ED care. However, an ED patient sample may have had a better representation of the most economically and socially disadvantaged groups, as EDs serve as a safety net of health care for these subpopulations. Second, the data collected were from a single urban tertiary hospital in a city with about $1 / 3$ of the population being Hispanic. The generalizability of the conclusions to other areas of the US could be limited. A third concern is that despite the pertinence and accuracy of BHLS, further research using other measurements of health literacy is warranted. Lastly, our knowledge of COVID-19 is dynamic and changing over time with new discoveries of treatment and prevention strategies. Items in our COVID-19 knowledge score may no longer be applicable at the present time.
This study found that even after controlling for patients' characteristics, patients with better general health literacy had better knowledge of basic epidemiology, prevention, diagnosis, treatment, and prognosis of COVID-19. This is in line with findings from studies of other infectious diseases that patients with lower health literacy had worse knowledge of antibiotics, decreased immunization rate and health screenings ${ }^{[4,6,22]}$. Reading comprehension, education level, English proficiency, and cultural differences were identified to be common additional contributing factor to health literacy ${ }^{[23]}$.

Despite these similarities, the ways the public acquire the knowledge of COVID-19 are distinctly different from those for other infectious diseases in the past, as COVID-19 is presented in a completely different epidemiological, cultural, technological, and even political context. The public have been exposed to some aspects of COVID-19 daily, as information and misinformation about COVID-19 permeate all media sources. Additionally, the drastic change in society with a near-nationwide shutdown and all individual lives being disrupted to some level created a unified 
front combating the transmission of COVID-19, making the efforts more focused than those for other infectious diseases in recent US history. Consequently, it is not surprising to find that overall, the participants of the current study had a good knowledge of COVID19.

Furthermore, even after controlling for confounding variables, this study found that ED patients with low income and those with lower education had a lower level of COVID-19 knowledge. Similar findings were demonstrated in an outpatient setting. In a study of adult outpatient clinic patients with at least 1 chronic condition, researchers found that blacks, the poor and those with low health literacy were less worried about COVID-19, less likely to believe that they would become infected and felt less prepared for an outbreak ${ }^{[24]}$. It is concerning that some studies identified that the same subpopulations had higher mortality and hospitalization rates of COVID-19 ${ }^{[25,26]}$, This pattern is consistent with prior studies that demonstrated lower education and income resulted in poor outcomes in other diseases ${ }^{[23,27-29]}$. It is likely that the worse health outcomes of these disadvantaged subpopulations are the result of the lack of effective COVID-19 prevention and coping strategies stemming from the inadequate COVID-19 knowledge. This is further complicated by the already existing barriers to medical care for these patients. Therefore, identifying ways to improve the COVID-19 knowledge within these subpopulations should become an integral part of any communitybased interventions and vaccination effort to better prepare the public for the pandemic and decrease the health disparities.

Various interventions have been shown to be effective for other diseases in the past, such as simplified wording during media presentations, numerical charts, addition of images and increased funding to media sources ${ }^{[30-32]}$. Applying similar strategies to COVID-19 education could yield similar favorable results. For example, one study demonstrated the effective use of infographics of COVID-19 on websites and social media ${ }^{[33]}$. In addition to improving the format of the information, targeting the social media platforms that are mostly frequently used by the disadvantaged subpopulations to disseminate the information of COVID-19 can be highly effective. However, as the World Health Organization (WHO) noted, the "infodemic" of COVID-19 presented a significant challenge to the local, national and global public health management as there was over-abundance of information and misinformation ${ }^{[34]}$. The potential misinformation presented in social media was illustrated in the current study, as we found that individuals whose primary sources of COVID-19 information was social media had the lowest COVID-19 knowledge score when compared to other sources.

\section{Conclusions}

COVID-19 presents a unique opportunity in that the current nationwide attention to this single disease is arguably higher than any other disease in recent time. To better prevent further increases in COVID-19 transmission and improve the rate of vaccination, community-based interventions can be more effective when targeting sociodemographic groups that have lower general health literacy. In particular, individuals of low educational levels and with low incomes should be prioritized. Less technical presentation of COVID-19 information and the targeting of specific media formats and platforms can significantly benefit individuals of lower socioeconomic and lower educational levels. Regulations on and/or guard against misinformation presented on social media platforms should be included in any effective interventions to improve individuals' knowledge of COVID-19, and likely the rate of vaccination in the communities.

\section{List of Abbreviations}

BHLS: Brief Health Literacy Screen

CDC: Centers for Disease Control

ED: Emergency Department

GCS: Glasgow Coma Scale

IRB: Institutional Review Board

REALM: Rapid Estimate of Adult Literacy in Medicine

S-TOFHLA: Short Test of Functional Health Literacy in Adults WHO: World Health Organization

\section{Conflict of Interest}

None of the above-listed authors have any conflict interest to declare

\section{References}

[1] Jingnan H. Why There are So Many Different Guidelines For Face Masks For The Public. 2020. Available at: https://www.npr.org/sections/goatsandsoda/2020/04/10/8 29890635/why-there-so-many-different-guidelines-forface-masks-for-the-public

[2] Use Masks to Help Slow Spread. 2020. Available at: https://www.cdc.gov/coronavirus/2019-ncov/preventgetting-sick/diy-cloth-face-coverings.html. Accessed August 14th, 2020

[3] Dewalt DA, Berkman ND, Sheridan S, et al. Literacy and health outcomes: a systematic review of the literature. J Gen Intern Med 2004;19:1228-1239

[4] Todorova I. Introduction to the special section: crosscultural beliefs, attitudes, and dilemmas about vaccination. Int J Behav Med 2014;21:1-2

[5] Omachi TA, Sarkar U, Yelin EH, et al. Lower health literacy is associated with poorer health status and outcomes in chronic obstructive pulmonary disease. J Gen Intern Med 2013;28:74-81

[6] Castro-Sánchez E, Chang PWS, Vila-Candel R, et al. Health literacy and infectious diseases: why does it matter? Int J Infect Dis 2016;43:103-110

[7] Olives TD, Patel RG, Thompson HM, et al. Seventy-twohour antibiotic retrieval from the ED: a randomized controlled trial of discharge instructional modality. Am J Emerg Med 2016;34:999-1005

[8] Peerson A, Saunders M. Health literacy revisited: what do we mean and why does it matter? Health Promot Int 2009;24:285-296

[9] Quinlan P, Price KO, Magid SK, et al. The relationship among health literacy, health knowledge, and adherence to treatment in patients with rheumatoid arthritis. Hss $j$ 2013;9:42-49

[10] Kalichman SC, Rompa D. Functional health literacy is associated with health status and health-related knowledge in people living with HIV-AIDS. J Acquir Immune Defic Syndr 2000;25:337-344

[11] Schillinger D, Grumbach K, Piette J, et al. Association of health literacy with diabetes outcomes. Jama 2002;288:475-482

[12] Williams MV, Baker DW, Parker RM, et al. Relationship of functional health literacy to patients' knowledge of 
their chronic disease. A study of patients with hypertension and diabetes. Arch Intern Med 1998;158:166-172

[13] Hansen HR, Shneyderman Y, Belcastro PA. Investigating the Association of Health Literacy With Health Knowledge and Health Behavior Outcomes in a Sample of Urban Community College Undergraduates. American Journal of Health Education 2015;46:274-282

[14] Williams M. A mixed methods study of health literacy and its role in hpv vaccine uptake among college students. 2014

[15] Huynh G, Nguyen T, Tran V, et al. Knowledge and attitude toward COVID-19 among healthcare workers at District 2 Hospital, Ho Chi Minh City. Asian Pacific Journal of Tropical Medicine 2020;13:260-265

[16] Baker DW, Williams MV, Parker RM, et al. Development of a brief test to measure functional health literacy. Patient Educ Couns 1999;38:33-42

[17] Carpenter CR, Kaphingst KA, Goodman MS, et al. Feasibility and diagnostic accuracy of brief health literacy and numeracy screening instruments in an urban emergency department. Acad Emerg Med 2014;21:137146

[18] Chew LD, Bradley KA, Boyko EJ. Brief questions to identify patients with inadequate health literacy. Fam Med 2004;36:588-594

[19] Cavanaugh KL, Osborn CY, Tentori F, et al. Performance of a brief survey to assess health literacy in patients receiving hemodialysis. Clin Kidney $\mathrm{J}$ 2015;8:462-468

[20] Goodman MS, Griffey RT, Carpenter CR, et al. Do Subjective Measures Improve the Ability to Identify Limited Health Literacy in a Clinical Setting? J Am Board Fam Med 2015;28:584-594

[21] Nilsen ML, Moskovitz J, Lyu L, et al. Health literacy: Impact on quality of life in head and neck cancer survivors. Laryngoscope 2019

[22] Herndon JB, Chaney M, Carden D. Health literacy and emergency department outcomes: a systematic review. Ann Emerg Med 2011;57:334-345

[23] Braveman P. Accumulating knowledge on the social determinants of health and infectious disease. Public Health Rep 2011;126 Suppl 3:28-30

[24] Wolf MS, Serper M, Opsasnick L, et al. Awareness, Attitudes, and Actions Related to COVID-19 Among Adults With Chronic Conditions at the Onset of the U.S. Outbreak: A Cross-sectional Survey. Ann Intern Med 2020;173:100-109

[25] Wadhera RK, Wadhera P, Gaba P, et al. Variation in COVID-19 Hospitalizations and Deaths Across New York City Boroughs. JAMA 2020;323:2192-2195

[26] Finch WH, Hernández Finch ME. Poverty and Covid-19: Rates of Incidence and Deaths in the United States during the First 10 Weeks of the Pandemic. Frontiers in Sociology 2020;5

[27] Weida EB, Phojanakong P, Patel F, et al. Financial health as a measurable social determinant of health. PLoS One 2020;15:e233359

[28] Zajacova A, Lawrence EM. The Relationship between Education and Health: Reducing Disparities through a Contextual Approach. Annu Rev Public Health 2018;39:273-289

[29] Pampel FC, Krueger PM, Denney JT. Socioeconomic Disparities in Health Behaviors. Annu Rev Sociol 2010;36:349-370

[30] Berkman ND, Sheridan SL, Donahue KE, et al. Health literacy interventions and outcomes: an updated systematic review. Evid Rep Technol Assess (Full Rep) 2011:1-941

[31] Schubbe D, Scalia P, Yen RW, et al. Using pictures to convey health information: A systematic review and meta-analysis of the effects on patient and consumer health behaviors and outcomes. Patient Educ Couns 2020

[32] Park J, Zuniga J. Effectiveness of using picture-based health education for people with low health literacy: An integrative review. Cogent Medicine 2016;3:1264679

[33] Chan AKM, Nickson CP, Rudolph JW, et al. Social media for rapid knowledge dissemination: early experience from the COVID-19 pandemic. Anaesthesia 2020

[34] Organization WH. Novel Coronavirus (2019-nCoV): situation report, 13. . In: Organization WH, ed.2020

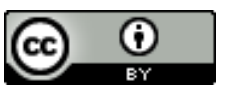

Open Access This article is licensed under a Creative Commons Attribution 4.0 International License, which permits use, sharing, adaptation, distribution and reproduction in any medium or format, as long as you give appropriate credit to the original author(s) and the source, provide a link to the Creative Commons license, and indicate if changes were made. The images or other third party material in this article are included in the article's Creative Commons license, unless indicated otherwise in a credit line to the material. If material is not included in the article's Creative Commons license and your intended use is not permitted by statutory regulation or exceeds the permitted use, you will need to obtain permission directly from the copyright holder. To view a copy of this license, visit https://creativecommons.org/licenses/by/4.0/.

(C) The Author(s) 2021 